\title{
No spatial patterns for early nectar storage in honeybee colonies
}

Michael Eyer ${ }^{1,2^{*}}$, Mark K. Greco ${ }^{3,4}$, Johann Lang ${ }^{5}$, Peter Neumann²,6, Vincent Dietemann ${ }^{1,6}$

1. Agroscope - Swiss Bee Research Centre, Schwarzenburgstrasse 161, 3003 Bern,

Switzerland

2. Institute of Bee Health, Vetsuisse Faculty, University of Bern, Switzerland

3. University of Bath Bee Unit Department of Biology and Biochemistry, United Kingdom

4. School of Biological, Earth and Environmental Sciences, University of New South Wales, Australia

5. Department for clinical veterinary medicine, Vetsuisse Faculty, University of Bern, Switzerland

6. Zoology and Entomology Department, University of Pretoria, Pretoria, South Africa

\footnotetext{
* Author for correspondence:

E-mail: michael.eyer@agroscope.admin.ch, phone: +41- (0)58-463 8204
} 


\begin{abstract}
Honeybees, Apis, forage for nectar and pollen, which are subsequently stored in cells of their nests. Despite the importance of honey storage for colony survival, very little is known about decision making by honey bee workers that could optimise the transformation of nectar into honey. Here we test, using Diagnostic Radioentomology, whether workers use rules based on sugar concentration to optimise the spatial distribution of storage cells during nectar ripening. The data show that after the first three days of storing activity, various sugar concentrations were mixed in individual cells. A spatial clustering of cells with content of similar concentration was only occasionally observed. The results therefore suggest that at early stages of storage, spatial proximity of cells with similar sugar concentrations does not result in improved efficiency and therefore does not seem adaptive. The costs involved in locating particular cells and transferring content probably outweighs the benefits of clustering. Alternatively, but not mutually exclusive, physiological constraints (e.g. variation in the perception of sugar concentration) might limit such optimisation behaviour. Storing behaviour can serve as a model to better understand food provisioning and complex organisation of insect societies.
\end{abstract}

Keywords: honeybees, nectar, honey storage, decision making, sugar concentration, diagnostic radioentomology 


\section{Introduction}

Honey bee workers, Apis spp., forage for sugar solutions in their environment as fuel for their metabolic processes. The sources of these carbohydrates are the nectar of flowers (White 1975; Seeley 1995), honeydew produced by various sap-sucking insects (Eickwort and Ginsberg 1980) and juices from open or weeping fruits or from other natural plant exudates (Roubik 1995; Michener 2000; O'Toole and Raw 2004). The availability of these resources is typically variable in time since their production is dependent on weather and climatic conditions. As a consequence, once brought into the nest by the foragers and once the metabolic needs of nestmates have been covered (Crailsheim 1990), the receiver bees (called food storers) place the surplus in honey storage cells of the nest. These accumulated reserves enable constant carbohydrate supply even in times of dearth or during the winter in the temperate regions when foraging is impossible.

To ensure efficient and sufficient food provisioning, honeybee workers are able to optimise their foraging activity according to the profitability of the carbohydrate sources available in their environment (Seeley 1986). Profitability is determined by the relationship between the energy required for retrieval, the availability and quality of the source as well as its distance away from the hive (Seeley 1991). Source quality is principally depending on sugar concentration. Foragers are able to detect levels of sugar concentration and to use this information in their foraging decision making (Farina and Núñez 1991; Seeley 1995; De Marco and Farina 2001).

Sugar concentration depends on the plant or aphid species from which the secretion is derived (Percival 1961), it also varies within a same species of flower according to environmental conditions since the water content of nectar changes with diurnal variations of temperature, atmospheric humidity and soil moisture (Corbet 2003). As a result, solutions of various sugar concentrations can be brought back to the nest for storage. If the behavioural 
processes contributing to carbohydrate foraging optimisation in a changing environment have been intensively studied (Seeley 1986, 1991 and 1995), there has been little research on decision making by honey bees for their storage strategies to cope with the variation in quality of nectar or secretions collected.

Storage optimisation could be performed by food storing and by honey processing bees (Nunez 1966; Farina 1996; De Marco and Farina 2001; Pirez and Farina 2004; Grueter and Farina 2007) and result in the storage of nectar or secretions of similar sugar concentration in neighbouring cells. An optimisation of the spatial arrangement of storage cells could promote the ripening process of nectar into honey, the final and long lasting storage form for carbohydrates (Park 1925, 1927, 1928, 1933, 1949, Maurizio 1975). Honey bee nest organization is divided in areas distinguished by their function (brood area, pollen storage and honey storage areas). Its ontogenesis is described as the result of a self-organized process based on simple decision rules (Camazine 1990, 1991, Johnson 2009, Montovan et al. 2013) probably leading to reduced energy expenditure (shorter transport times and distances) and hence to task optimization (Dreller and Tarpy 2000, Schmickl and Crailsheim 2004, Hepburn et al. 2014,). A spatial pattern in the early carbohydrate storage could restrict the tasks necessary for honey ripening to distinct areas of the comb and thus contribute to reduced energy consumption (Greco et al 2013). Such tasks include active evaporation of cell content by food processors (Park 1925, 1927, 1928, 1933, 1949), or ventilation which has been proposed as a mechanism to regulate atmosphere humidity of honey stores to favour passive evaporation (Reinhardt 1939, Human et al 2006;). By adjusting humidity according to the optimal value required for the cells on spatially defined clusters, conflicts with nest areas requiring different humidity optima (Human et al 2006) would be reduced, so that energy consumption for the process could decrease and speed of evaporation could increase. 
In support of this hypothesis, clustering of cells with content of similar concentration was shown within the first $48 \mathrm{~h}$ of access to a sugar solution (Greco et al. 2013). By building on their methods and by using less restrictive experimental conditions (reflecting a biologically more relevant situation), we aimed at consolidating and generalising these findings. By monitoring the end destination of solutions of different sugar concentrations covering the whole range available in nature (30-70\%), we deduced the filling process of storage cells in larger colony units and over a longer time period allowing for a higher quantity of solution to be deposited into the cells. Our results suggest that the occurrence of storage rules is not consistent throughout the ripening process or depend on colony size. We discuss why such strict spatial pattern might not be adaptive.

\section{Material and Methods}

\section{Hive Preparation and Feeding Regime}

Hive and colony size were chosen so as to ensure normal colony functioning while obtaining the highest resolution possible allowing us to investigate cell content in detail. We used 9 small hives (Miniplus (R)) filled with 4,000 workers each (compared to $~ 1,000$ in Greco et al. 2013). Such size corresponds to experimental unit able to express all normal behaviours of a full sized colony (Seeley 1995, Jeanson et al., 2007). Hives were filled with combs previously drawn from foundation wax sheets in other colonies. One mated and actively laying queen was housed in each hive. The hives were closed during the 3 day experimental period to prevent bees foraging on external food sources. During this time, the hives were kept in a cool room at $14{ }^{\circ} \mathrm{C}$ to prevent overheating of the closed compartment. Apart from colony size, hive type and experiment duration, the same experimental and feeding conditions as in Greco et al. (2013) were used. 
Within each hive, the bees were given access to two separate feeders containing the solutions of different sucrose concentration. All colonies received a 50\% sucrose solution. Three colonies received in the second feeder labelled solutions of $30 \%$ sucrose, 3 other colonies received labelled solutions of $50 \%$ and the 3 remaining colonies received labelled solutions of $70 \%$ sucrose in the second feeder. These concentrations were chosen within the natural range for nectar sugar concentration collected by honey bees (Seeley 1995) and as distinct from each other as possible to promote their discrimination by the honey bees. The three feeding diets are hereafter coded as 30/50, 50/50 and 70/50 based on the concentration of sugar of the feeding solutions. Feeders were weighed and refilled every day for 3 days in the colonies. The 3 days enabled time for the bees to store the solutions and fill some cells completely. One of the colonies given the 70/50 diet dwindled to death during the experiment and did not store the solutions provided. It was thus excluded from the study. After 3 days, the experiment was interrupted by collecting the combs out of the hives and storing them at $14^{\circ} \mathrm{C}$ until computer tomography scanning was performed to measure density of cell content.

\section{Diagnostic Radioentomology}

We used Diagnostic Radioentomology to trace solutions of different sucrose concentrations after they were stored in the comb. This technique is based on the measurement of density, the visualisation and quantification of the differences in density of the component materials with computer tomography scanning (Greco et al. 2005). Scans were performed on a Philips Brilliance CT 16-slice apparatus (Philips Healthcare, 5680 DA Best, The Netherlands) using 120.0 $\mathrm{kVp}$ and $183.0 \mathrm{~mA}$ as settings. Since temperature influences density of materials, constant conditions during scanning were ensured by holding the temperature in the scanning room at $18-20^{\circ} \mathrm{C}$. Density, quantified in Hounsfield Units (HU), was measured using $e$ FilmLite version 1.5.0.0-DICOM (Digital Imaging and Communications in Medicine 
NEMA). The density of individual cell content was measured with the ellipse tool of $e$ Film drawing an ellipse over each cell to be measured. For this, a plane was chosen that crossed a maximum number of cells of which the whole diameter was occupied by sucrose solution. Cells of lower filling status, of which the diameter in this plane was only partially occupied by solution were excluded from the measurement to avoid biases caused by air. The inclusion of air volumes in the measurement ellipse results in a decrease of Hounsfield unit values, the air being less dense than the solution. In order to increase our ability to discriminate between sucrose solutions of different concentrations, we labelled one of the two feeding solutions available to the bees with a contrast agent $[10 \%$ Visipaque 320 radiographic contrast agent (GE Healthcare Inc, Easton Turnpike Fairfield, CT, United States)].

\section{Method Validation}

In order to exclude potential methodological biases that could influence our interpretation of density measures and patterns observed in our test combs, we have performed several validation experiments.

\section{Density as a Proxy for Sugar Concentration}

In order to establish the relation between sugar concentration and contrast agent labelling with the density of the solutions, we produced a calibration curve (Fig. 1). We used solutions with $30,50,60,70$ and $80 \%$ sucrose that cover the range of concentration required for the experiment. Two vials were filled with each concentration. In one of them contrast agent (Visipaque) was added to a concentration of $10 \%$. The vials were then scanned and the density of 10 randomly selected points in each vial was measured and averaged. 


\section{Effect of the Labelling Technique on Results}

Contrast agents used in Diagnostic Radioentomology studies are by definition dense and could gravitate passively to the bottom of the solution stored in the cell. This could, with time, create a density gradient within the cells and require several measurements to obtain an average value that represents the cumulated storing behaviour of workers at the end of the experimental period. In order to optimise the measurement process and be able to analyse large number of cells, we determined the optimal time, after cessation of storage, at which we could perform a single measurement for each cell. For this, we monitored, over time, the density at several depths within a vial containing pure labelled $50 \%$ sucrose solution. If a $50 \%$ labelled solution remains homogeneous, it remains possible that upon mixture, a labelled and a non-labelled solution separate due to gravity, with the contrasted solution sinking below the non-contrasted solution. To verify this, we repeated this test using vials containing contrasted sugar solution (50\% labelled) placed on top of non-contrasted solution (50\% unlabelled).

The vials were scanned 1h, 3 days and 4 weeks after preparation. After the first scan, vials were kept at $14^{\circ} \mathrm{C}$ to prevent fermentation of the sugar solutions. Point measurements of solution density were taken at 3 different horizontal levels in the vials: at the bottom, in the middle and at the top of the solution. Nine regularly spaced measurement points were chosen per level. These 9 points were on the same vertical axis at each level and their average was calculated to obtain one Hounsfield unit value per level. These tests enabled us to determine in which manner (at which point in time and space) to measure density of cell content in order to obtain representative values for our analysis of storage patterns. 


\section{Statistical Analyses}

\section{Effect of the Labelling Technique on Results}

The homogeneity of solutions in the test vial was verified by comparing the Hounsfield unit value of each level within the vial using a Kruskal-Wallis test since HU-values in some of the replicates were not normally distributed.

\section{Effect of Sugar Concentration on Storage}

In order to compare the distribution of Hounsfield unit values around the means within diets (30/50, 50/50 and 70/50) without a putative influence of the preference for one of the solutions by the colonies or of concentration process, we standardised the data. This was done by removing the mean of the Hounsfield unit values measured in a replicate to each cell density value in this replicate ( $\mathrm{N}=8$ combs containing from 69 to 107 randomly selected cells of both comb sides) and dividing it by the standard deviation of the sample. The average of each replicate is thus brought to 0 and the standard deviation to 1 . The replicates within a diet can thus be pooled and the distribution of values around the mean be investigated on a larger sample size. A normal distribution is expected if the sucrose solutions are randomly deposited in cells by bees for storage. We tested with the Kolmogorov-Smirnov statistics whether Hounsfield unit values of the stored sucrose solution are distributed normally. A nonsignificant result would show that cells containing random proportions of solutions are present on the comb and that there is no segregation of solutions of different sugar concentration in different cells. In other words, non-significance would show that the whole range of mixture of both solutions is found in the cells. Analyses were performed with the program SYSTAT 12. 
Even if combs contain the whole range of sucrose concentration, workers could store content of similar concentration in neighbouring cells, creating clusters on the comb. To determine whether such spatial patterns occur, a single vertical scan frame perpendicular to the cells long axis and parallel to the comb mid rib was selected for each comb of the three groups $(30 / 50 ; \mathrm{N}=3),(50 / 50 ; \mathrm{N}=3),(70 / 50 ; \mathrm{N}=2)$. Combs $(\mathrm{N}=8)$ for which spatial patterns were investigated contained from 88 to 264 cells. The projected coordinates of each cell measured (their $\mathrm{X}$ and $\mathrm{Y}$ coordinates) were obtained with the Probe Tool of $e$ FilmLite.

To determine whether cells of similar densities (a proxy for sucrose concentration) were spread randomly, uniform or clustered, the spatial autocorrelation Morans I test statistic was used. This test incorporates feature locations and attribute values to calculate the spatial autocorrelation (I index). I-indices close to zero indicate random pattern, whereas positive indices indicate a tendency toward clustering and negative indices indicate a tendency toward uniformity. The $\mathrm{p}$ value and the corresponding standard deviation (z-scores) reflect the probability that the observed spatial pattern is created by a random process. As conceptualization model for the analysis, we chose the fixed distance model with a value of 15.5, which represents the mean distance between the centers of two neighboring cells. This ensured that neighboring values are highly weighed in the spatial autocorrelation measurements. ArcGIS 10.2 software was used for this analysis. 


\section{A Posteriori Method Validation}

\section{Effect of Preference Based on Labelling or Sugar Concentration}

Observations of storage pattern can be affected if honeybees have a preference for consumption or storage of labelled or unlabelled sucrose solution. We tested this possibility in the 50/50 group since the concentration of both solutions is equal and only the presence of the contrast agent could have an effect. Each colony had one feeder containing 50\% unlabelled and the other $50 \%$ labelled solution. If one of the solutions is preferred for storage, it becomes visible with a shift of density measurements of the cell contents towards the Hounsfield unit value of the preferred solution.

Once the effect of the contrast agent on preference was determined, we tested for preference in storage based on sugar concentration in the groups 30/50 and 70/50 ( $\mathrm{N}=3$ colonies each, see above). In order to test statistically whether bees preferentially stored one of the solutions a one sample t-test was performed. We compared the expected Hounsfield unit value (average of density when solutions are mixed equally, for example in the case of 30/50 group: $\left(\mathrm{HU}_{30 \mathrm{~L}}+\mathrm{HU}_{50 \mathrm{U}}\right) / 2$, with $\mathrm{HU}_{30 \mathrm{~L}}$ and $\mathrm{HU}_{50 \mathrm{U}}$ the values of pure solutions $30 \%$ labelled and $50 \%$ unlabelled, respectively) to the measured (mes.) average from 69-107 randomly selected cells of both comb sides per replicate.

Since Hounsfield unit values were not normally distributed in some of the replicates, a nonparametric binomial test was performed to confirm the result. For this test, we determined the proportion of events with values superior to the predicted Hounsfield unit value and compared it with equal distribution of stored solutions (proportion of values inferior to the expected value $=$ proportion of values superior to the expected value $=0.5$ )

From the average Hounsfield unit value for each replicate, we deduced the proportion of each solution stored with the following formula: 
$\mathrm{x} \cdot H \mathrm{U}_{1}+(1-\mathrm{x}) \cdot \mathrm{HU}_{2}=\mathrm{HU}_{\mathrm{mes}}$

leads to

$x=\left(\mathrm{HU}_{\text {mes. }}-\mathrm{HU}_{2}\right) /\left(\mathrm{HU}_{1}-\mathrm{HU}_{2}\right)$

with $\mathrm{HU}_{1}$ and $\mathrm{HU}_{2}$ the value of pure solutions 1 and 2, $x$ the proportion of solution 1 stored in the cells and $\mathrm{HU}_{\text {mes. }}$ the average Hounsfield unit value measured from the cells.

Preference for the collection of a solution was also tested by comparing the amount of solution removed from the dishes to that placed in the hive by the bees.

\section{Effect of Nectar Ripening}

If workers actively concentrate the solutions stored to produce honey, their concentration will increase independently of the addition of a more concentrated solution and generate a bias. Evidence that this phenomenon occurs can be deduced from the highest Hounsfield unit values observed. If the measures show values larger than the maximum Hounsfield unit value (that of the pure labelled solution of highest concentration in each group), concentration by workers likely occurred. Absence of such high values will also show that the solutions did not evaporate passively before Diagnostic Radioentomology scanning. 


\section{Results}

\section{Method Validation}

The calibration curves obtained show that pure labelled and unlabelled sucrose solutions can easily be discriminated based on their density and independently of their sucrose concentration (Fig. 1). Sugar concentration influences the density of the solutions, but to a lesser extent. Hounsfield unit between the ranges for labelled and unlabelled solutions result from the mixing of both solutions.

\section{Effect of the Labelling on Observations}

A difference in the density of the different levels within a vial of pure labelled solution was observed 3 days, but not after $1 \mathrm{~h}$ or 4 weeks after preparation (Kruskal-Wallis test: $\mathrm{K}_{1 \mathrm{~h}}=3.5$, $\mathrm{DF}_{1 \mathrm{~h}}=2, \mathrm{P}_{1 \mathrm{~h}}=0.18 ; \mathrm{K}_{3 \mathrm{~d}}=9.4, \mathrm{DF}_{3 \mathrm{~d}}=2, \mathrm{P}_{3 \mathrm{~d}}<0.01 ; \mathrm{K}_{4 \mathrm{w}}=4.58, \mathrm{DF}_{4 \mathrm{w}}=2, \mathrm{P}_{4 \mathrm{w}}=0.10$, Fig. 2).

Labelled solution sank below non labelled solution immediately after pouring the former on top of the latter. This generated two well separated layers visible in the first scan, one hour after mixing the solutions. The difference in density between layers was highly significant $\left(\mathrm{K}_{1 \mathrm{~h}}=22.3, \mathrm{DF}_{1 \mathrm{~h}}=2, \mathrm{P}_{1 \mathrm{~h}}<0.01\right)$ with the bottom layer showing a high density. Three days later there was a more gradual transition zone between these layers, but the differences in density were still highly significant $\left(\mathrm{K}_{3 \mathrm{~d}}=23.5, \mathrm{DF}_{3 \mathrm{~d}}=2, \mathrm{P}_{3 \mathrm{~d}}<0.01\right)$. After 4 weeks, significance level of density differences between layers was above $0.01\left(\mathrm{~K}_{4 \mathrm{w}}=8.35, \mathrm{DF}_{4 \mathrm{w}}=2, \mathrm{P}_{4 \mathrm{w}}=0.02\right)$, with the density of the bottom layer decreasing and the middle and top layers increasing (Fig. 3), resulting in a more homogeneous solution. 


\section{Storage Preference Based on Labelling}

Fifty percent sucrose solution with contrast agent and 50\% unlabelled sucrose solution were found in non-significantly different proportions in combs of two colonies of the 50/50 diet (one sample $\mathrm{t}$-test: $\mathrm{t}_{50 \mathrm{~L} / 50 \mathrm{U}_{-} 1}=-0.95, \quad \mathrm{~N}_{50 \mathrm{~L} / 50 \mathrm{U}_{-} 1}=107, \quad \mathrm{p}_{50 \mathrm{~L} / 50 \mathrm{U}_{-} 1}=0.35 ; \quad \mathrm{t}=50 \mathrm{~L} / 50 \mathrm{U}_{-} 3=0.54$, $\mathrm{N}_{50 \mathrm{~L} / 50 U_{-} 3}=101, \mathrm{P}_{50 \mathrm{~L} / 50 U_{-} 3}=0.59$; Fig. 4). Since Hounsfield unit values for these replicates were not normally distributed, we confirmed this result with a binomial test $\left(Z_{50 L / 50 U_{-} 1}=-1.65\right.$, $\left.\mathrm{N}_{50 \mathrm{~L} / 50 \mathrm{U}_{-} 1}=107, \mathrm{P}_{50 \mathrm{~L} / 50 \mathrm{U}_{-} 1}=0.10 ; \mathrm{Z}_{50 \mathrm{~L} / 50 \mathrm{U}_{-} 3}=-0.69, \mathrm{~N}_{50 \mathrm{~L} / 50 \mathrm{U}_{-} 3}=101, \mathrm{P}_{50 \mathrm{~L} / 50 \mathrm{U}_{-} 3}=0.49\right) . \mathrm{In}$ the third replicate there was a slight, significantly higher amount of labelled solution stored $\left(\mathrm{t}=50 \mathrm{~L} / 50 \mathrm{U}_{-} 2=6.3, \mathrm{~N}_{50 \mathrm{~L} / 50 \mathrm{U} \_2}=69, \mathrm{P}_{50 \mathrm{~L} / 50 \mathrm{U} \_2}<0.01\right.$; Fig. 4). The absence of clear preference (in majority) towards one of the solutions is in line with the overlap of the average of the Hounsfield unit values measured with the value of 684.5 expected when the two solution are mixed in equal proportions (Fig. 5).

\section{Storage Preference Based on Sugar Concentration}

The measures in 30/50 colonies showed that a higher quantity of 50\% unlabelled sucrose solution was stored compared to $30 \%$ labelled sucrose solution in all replicates $\left(t_{30 / 50} 1=-9.7\right.$, $\mathrm{N}_{30 / 50 \_1}=79 ; \mathrm{t}_{30 / 50 \_2}=-9.6, \mathrm{~N}_{30 / 50 \_2}=76 ; \mathrm{t}_{30 / 50 \_3}=-16.9, \mathrm{~N}_{30 / 50 \_3}=80, \mathrm{P}<0.01$ in all cases; Fig. 4). Since more unlabelled solution was stored, the average of the Hounsfield unit values measured is lower than the value of 626.5 expected when these solutions are mixed in equal proportions (Fig. 5). Hounsfield unit values of replicate 2 were not normally distributed. The binomial test confirmed the significantly higher amount of 50\% sucrose solution $\left(\mathrm{Z}_{30 / 50 \_2}=-8.31, \mathrm{~N}_{30 / 50 \_2}=76, \mathrm{P}_{30 / 50 \_2}<0.01\right)$.

Significant deviation from the storing of equal proportion of each solution could also be measured in the $70 / 50$ diet $\left(\mathrm{t}_{70 / 50 \_1}=-5.4, \mathrm{~N}_{70 / 50 \_1}=74 ; \mathrm{t}_{70 / 50 \_2}=4.7, \mathrm{~N}_{70 / 50 \_2}=81, \mathrm{P}<0.01\right.$ in both 
cases; Fig. 5). However, in one case the proportion of 50\% was higher in the combs and in the other case the proportion of $70 \%$ sucrose was higher.

Calculated proportions of each solution stored were $2.3 \pm 0.4,0.9 \pm 0.2$ and $1.2 \pm 0.5$ for the $30 / 50,50 / 50$ and 70/50 diets, respectively. When measuring the amount of solutions removed from the feeding dishes, workers collected $4.2 \pm 1.1$ times more of the $50 \%$ unlabelled sucrose solution than of $30 \%$ labelled solution. They collected $1.3 \pm 0.5$ and $1.5 \pm 0.8$ times more of the $50 \%$ unlabelled sucrose solution than of the labelled 50 and $70 \%$ sucrose solutions, respectively.

\section{Processing of Solutions by Workers During Nectar Ripening}

In none of the replicates did we find Hounsfield unit values superior to the theoretical Hounsfield unit value of pure solutions (e.g. $\mathrm{HU}_{50 \mathrm{~L}}=1153$ for $50 \%$ labelled / 50\% unlabelled experiment, e.g. Fig. 6).

\section{Spatial Rules for Storage}

To avoid any confounding influence (see methods) on rules for storage we used standardised data of the replicates. Standardised Hounsfield unit values within each of the diets showed a normal distribution of sugar concentration in the cells measured on all combs (Kolmogorov-Smirnov-Test: Maximum Difference $30 / 50=0.05 ; \quad \mathrm{N}_{30 / 50}=235, \quad \mathrm{P}_{30 / 50}=0.08$; Maximum Difference $50 / 50=0.08, \mathrm{~N}_{50 / 50}=277, \mathrm{P}_{50 / 50}=0.47$; Maximum Difference $70 / 50=0.05$, $\left.\mathrm{N}_{70 / 50}=155, \mathrm{P}_{70 / 50}=0.78\right)$. 
The results obtained with the spatial autocorrelation analysis (Morans I) show that for two out of the three combs of the $30 / 50$ diet, one out of the three combs of the $50 / 50$ diet and the 2 combs of the 70/50 diet, the cells with similar densities tended towards clustering.

This clustering was significant in 3 out of the five cases (Morans I test: Morans I-index 30/50_3 $=0.35, \quad$ Z-score $30 / 50 \_3=5.54, \quad \mathrm{~N}_{30 / 50 \_3}=121, \quad \mathrm{P}_{30 / 50 \_3}<0.01 ;$ Morans Iindex70/50_1 $=0.09, \mathrm{z}$-score $70 / 50 \_1=2.59, \mathrm{~N}_{70 / 50 \_1}=264, \mathrm{P}_{70 / 50 \_1}<0.01$; Morans I-index $70 / 50 \_2=0.244$, Z-Score $70 / 50 \_2=3.56, \mathrm{~N}_{70 / 50 \_}=88, \quad \mathrm{P}_{70 / 50 \_2}<0.01$ ), but not significant in the two other cases (Morans I-index $30 / 50 \_2=0.08, \quad$ z-score $30 / 50 \_2=1.77, \mathrm{~N}_{30 / 50 \_2}=156, \mathrm{P}_{30 / 50 \_2}=0.08 ;$ Morans Iindex $50 / 50 \_2=0.08, \mathrm{z}$-score $\left.50 / 50 \_2=1.77, \mathrm{~N}_{50 / 50 \_2}=180, \mathrm{P}_{50 / 50 \_2}=0.08\right)$. In contrast, the cells of similar density of one comb of the 30/50 diet and two combs of the 50/50 diet were randomly distributed over the comb (Morans I-index $30 / 50 \_1=-0.08$, Z-score $30 / 50_{-} 1=-1.05, \mathrm{~N}_{30 / 50 \_1}=116$, $\mathrm{P}_{30 / 50 \_1}=0.29 ;$ Morans I-index $50 / 50 \_1=0.05, \mathrm{z}-$ score $_{50 / 50 \_1}=1.04, \mathrm{~N}_{50 / 50 \_1}=152, \mathrm{P}_{50 / 50 \_1}=0.30$; Morans I-index $50 / 50 \_3=0.06, \mathrm{z}$ - score $\left._{50 / 50 \_3}=1.25, \mathrm{~N}_{50 / 50 \_3}=150, \mathrm{P}_{50 / 50 \_3}=0.21\right)$.

\section{Discussion}

Our results show that at the early stages of nectar storage, honey bee workers mix solutions of different sugar concentrations in cells. Moreover, clustering of cells with similar concentrations occurred only occasionally, thereby indicating that workers do not follow a consistent rule for spatial nectar storage at this stage of honey production. Our conclusions differ from those of Greco et al. (2013) who suggested occurrence of clusters of cells containing similar content in smaller colony units and after a shorter storage period. This shows that honey ripening processes need to be considered under various conditions to provide a more general understanding of the storage behaviour of honeybees. 
The data show that sedimentation of the contrast agent used to highlight differences in sugar concentration is unlikely to influence the measurements. Since the density in the mixed solution appeared more homogeneous after four weeks, we measured density of the cell content four weeks after cessation of storage in the experimental hives. Similar to earlier reports (Greco et al. 2013), no preference for labelled or unlabelled solutions with similar sugar concentrations $(50 \mathrm{~L} / 50 \mathrm{U})$ was detected, thereby supporting that storage behaviour of workers was not influenced by labelling method. Both low and high sugar concentrations were stored in all replicates, enabling us to monitor the end result of this process. Since Hounsfield unit values never exceeded their theoretical maximum value, there was no evidence for intense active evaporation of sucrose solution by the workers during the three days of feeding and storage or of passive evaporation during the weeks of comb storage before scanning. Therefore, the observed densities were resulting from storage rules and putative preference for sugar concentration by workers and not from a methodological bias.

A consistent preference was observed for $50 \%$ over $30 \%$ sucrose solution. We found a difference in the ratio of solutions removed from the feeding dishes and that of solutions stored in the cells. For instance, four times more 50\% sucrose solution was removed from the dishes than that of $30 \%$ solution, whereas for the quantities stored in the cells, we found a lower ratio of 2:3. The trend between 50 and $70 \%$ solutions was inversed with a preference for consumption of the lower concentration, but it was not as pronounced as for the 30/50 diet. This discrepancy in ratios of amounts removed from the feeders and stored in the comb might lay in the sugar solution bees consumed. Bees appeared to store more of the solutions of weaker $(30 \%)$ and higher $(70 \%)$ sugar concentration, but consume more of the solution with intermediate $(50 \%)$ sugar concentration. This could result from the fact that worker can best metabolise solution at this concentration for their physiological needs under our experimental conditions (flightless cold room) and store the solutions of lower and higher 
concentration. These lower and higher concentrated solutions could later be concentrated or diluted to a more appropriate value needed for consumption or long term storage. The economy of food consumption and storage within honey bee colonies deserves better description in a context where nutrition is increasingly considered as an important factor for honeybee health (Brodschneider \& Crailsheim 2010, Erler et al. 2014).

In most replicates, the Moran I index used to quantify spatial aggregation was close to 0 , indicating random spatial distributions, with a weak, but sometimes significant tendency towards clustering. Whether workers use an optimal strategy to store nectar later during reserve accumulation should be investigated over an even longer period of nectar storage and ripening. Comparing our results with those of Greco et al. (2013), it appears that colony size and length of time from collection influences storing patterns. Spatial clustering of cell content according to sugar concentration could disappear with increasing worker population. With more individuals involved in the process, the end product of rules could become a blur. Indeed, the combination of a high number of visits necessary to fill a cell and individual variations in perception of sugar concentration (Scheiner et al. 2004), inconsistencies are likely to accumulate. It can thus be expected that mixing solutions of different sugar concentration is more probable than filling cells with carbohydrate of the same origin or sugar concentration. Thus, variability in perception of sugar concentrations may prevent the spatial optimisation of carbohydrate storage based on this parameter. A similar constraint limiting optimisation was suggested to explain the inaccuracy of the dance communication to recruit foragers to food sources (Tanner \& Vischer 2010, Preece and Beekman, 2014). The vector component of the dance while transferring information about the location and distance of a current food source contains an inherent error due to physiological and sensory constraints among individual bees (Preece and Beekman 2014). As a consequence, dance followers trying to compensate for this non-adaptive error by following several waggle runs, thus increase 
their chances of source detection. This suggests that optimisation at the colony level might also be restricted due to physiological constraints of individual bees.

The results show no strong evidence for optimised storage behaviour, suggesting that early spatial clustering of cells according to the sugar concentration of their content does not result in increased efficiency. Food-storer bees seem to randomly deposit their carbohydrate loads in the combs, instead of spending time to find cells with matching sugar concentrations. This idea is supported by the results of De Grandi-Hoffman and Hagler (2000) who found that $70 \%$ of nectar cells had some content added to within 24 hours. The continuous addition of nectar to a large number of cells is less likely to correspond to the filling of only cells with a similar sugar concentration. This is also in line with Camazine (1991) who proposed that the pattern of comb usage typical for honeybees likely derives from a self-organizing mechanism based on the interactions among deposition and relocation processes of cell content without a plan specifying spatial relationship. Even though nectar is first deposited randomly around the comb, after successive relocations fostered by consumption, ripening or brood dynamics, honey stores accumulate above the brood and pollen as well as on the lateral combs (Camazine 1990, Schmickl \& Crailsheim 2004).

Diagnostic Radioentomology, a non-invasive and reliable method was proven appropriate to study honey storing with a higher resolution compared to the data available to date. This method could be used to better describe food storage behaviour, a poorly understood function of the honey bee society, which is however at the root of their extensive commercial exploitation and of their use as a model organism for research. The data do not support optimised early storage of nectar according to sugar concentration, thereby suggesting that the cost to benefit ratio for such behaviour is not favourable, and that a random deposition of collected carbohydrates in the combs does not preclude efficient storage behaviour of honey bees. 


\section{Acknowledgements}

We are grateful to R. Joss for the help with the experiments. We thank W. Lüginbühl for his assistance with the statistics and S. Rogers for support with the spatial analysis. Mark Greco was partly funded by the Eva Crane Trust for this research.

\section{References}

Brodschneider R, Crailsheim K (2010) Nutrition and health in honey bees. Apidologie $41: 278-294$

Camazine S, Sneyd J, Jenkins MJ, Murray JD (1990) A mathematical model of self-organized pattern formation on the combs of honeybee colonies. J Theor Biol 147:553-571

Camazine S (1991) Self-organizing pattern formation on the combs of honey bee colonies. Behav Ecol Sociobiol 28:61-76.

Corbet SA (2003) Nectar sugar content: estimating standing crop and secretion rate in the field. Apidologie 34:1-10

Crailsheim K (1990) Protein synthesis in the honeybee (Apis mellifera L.) and trophallactic distribution of jelly among imagos in laboratory. Zool Jb Physiol 94:303-312

Dreller C, Tarpy DR (2000) Perception of the pollen need by foragers in a honeybee colony. Anim Behav 59:91-96

De Marco RJ, Farina WM (2001) Changes in food source profitability affect the trophallactic and dance behavior of forager honeybees (Apis mellifera L.). Behav Ecol Sociobiol $50: 441-449$ 
Eickwort G, Ginsberg H (1980) Foraging and Mating Behaviour in Apoidea. Annu Rev Entomol 25:421-426

Erler S, Denner A, Bobiş O, Forsgren E, Moritz, R. F. (2014) Diversity of honey stores and their impact on pathogenic bacteria of the honeybee, Apis mellifera. Ecology and evolution 4:3960-3967

Farina WM (1996) Food-exchange by foragers in the hive - A means of communication among honey bees? Behav Ecol Sociobiol 38:59-64

Farina WM, Núñez JA (1991) Trophallaxis in the honeybee "Apis mellifera" (L.) as related to the profitability of food sources. Anim Behav 42:389-394

Greco M, Spooner-Hart R, Holford P (2005) A new technique for monitoring Trigona carbonaria nest contents, brood and activity using X-ray computerised tomography. J Apic Res 44:97-100

Greco MK, Lang J, Gallmann P, Priest N, Feil E, Crailsheim K (2013) Sugar concentration influences decision making in Apis mellifera L. workers during early-stage honey storage behaviour. Open J Anim Sci 3:210-218

Grueter C, Farina WM (2007) Nectar distribution and its relation to food quality in honeybee (Apis mellifera) colonies. Insectes Soc 54:87-94

Hepburn HR, Pirk CWW, Duangphakdee O (2014) Honeybee Nests; Composition, Structure, Function. Springer-Verlag Berlin

Human H, Nicolson SW, Dietemann V (2006) Do honeybees, Apis mellifera scutellata, regulate humidity in their nest? Naturwissenschaften 93:397-401

Jeanson R, Fewell JH, Gorelick R, Bertram, SM. (2007) Emergence of increased division of labor as a function of group size. Behav Ecol Sociobiol 62: 289-298 
Johnson BR (2009) A Self-Organizing Model for Task Allocation via Frequent Task Quitting and Random Walks in the Honeybee. Amer Nat 174: 537-547

Maurizio A (1975) Microscopy of honey. Honey: A Comprehensive Survey. E. Crane, ed, London

Michener CD (2000) The bees of the world (Vol. 1). John Hopkins University Press

Montovan KJ, Karst N, Jones LE, Seeley TD (2013) Local behavioral rules sustain the cell allocation pattern in the combs of honey bee colonies (Apis mellifera). J Theor Biol 336: $75-86$

Nunez JA (1966) Quantitative Beziehungen zwischen den Eigenschaften von Futterquellen und dem Verhalten von Sammelbienen. Z vergl Physiol 53:142-164

O'Toole C, Raw A (2004) Bees of the world. London, Cassell Illustrated

Park OW (1925) The storing and ripening of honey by honeybees. J Econ Entomol $18: 405-410$

Park OW (1927) Studies on the evaporation of nectar. J Econ Entomol 20:510-516

Park OW (1928) Further studies on the evaporation of nectar. J Econ Entomol 21:882-887

Park OW (1933) Studies on the rate at which honeybees ripen honey. J Econ Entomol 26:188-193

Park OW (1949) How bees make honey. In: Grout RA (ed), Hamilton III, The hive and the honey bee. Dadant \& Sons, pp 125-152

Percival MS (1961) Types of nectar in Angiosperms. New Phytol 60:235-281 
Pirez N, Farina WM (2004) Nectar-receiver behavior in relation to the reward rate experienced by foraging honeybees. Behav Ecol Sociobiol 55:574-582

Preece K, Beekman M (2014) Honeybee waggle dance error: adaption or constraint? Unravelling the complex dance language of honeybees. Anim Behav 94: 19-26

Reinhardt JF (1939) Ventilating the bee colony to facilitate the honey ripening process. J Econ Entomol 32:654-660

Roubik DW (1995) Pollination of Cultivated Plants in the Tropics. FAO Bulletin of Agricultural Services 118:1-194

Seeley TD (1986) Social foraging by honeybees: how colonies allocate foragers among patches of flowers. Behav Ecol Sociobiol 19:343-354

Seeley TD, Camazine S, Sneyd J (1991) Collective decision-making in honey bees: how colonies choose among nectar sources. Behav Ecol Sociobiol 28: 277-290

Seeley TD (1995) The wisdom of the hive: the social physiology of honeybee colonies. Harvard University Press

Scheiner R, Page RE, Erber J (2004) Sucrose responsiveness and behavioral plasticity in honey bees (Apis mellifera). Apidologie 35:133-142

Schmickl T, Crailsheim K (2004) Inner nest homeostasis in a changing environment with special emphasis on honey bee brood nursing and pollen supply. Apidologie 35: 249-263

Tanner DA, Visscher PK (2010) Adaptation or constraint? Reference-dependent scatter in honey bee dances. Behav Ecol Sociobiol 64: 1081-1086

White JW (1975) Composition of honey. In: Crane E (ed) Honey: a comprehensive survey. London, Heinemann 
Fig. 1 The calibration curve plotting Hounsfield Unit values (HU) according to sugar concentration, for solutions unlabelled or labelled with $10 \%$ Visipaque contrast agent. Average \pm SD are given for the 10 points measured per concentration

Fig. 2 Average \pm SD density measurments $(n=9)$ at 3 height levels within a vial containing $50 \%$ sugar solution labelled with contrast agent. A Kruskal-Wallis test reveals that after 3 days a difference in the density of the different levels within the vial occur, but no difference was observed after $1 \mathrm{~h}$ or 4 weeks

Fig. 3 Average \pm SD density measurements $(n=9)$ at 3 height levels within a vial in which $50 \%$ sugar solution with contrast agent was poured on top of $50 \%$ unlabelled sugar solution. Measures were performed one hour, 3 days and 4 weeks after mixing. Applied Kruskal-Wallis test reveals that after 1 hour and 3 days a significant difference in the density of different levels within the vial occur, whereas after 4 weeks significance level of density differences was above 0.01 , resulting in a more homogeneous solution

Fig. 4 Proportion of each solution stored in cells of each replicate. The sugar concentrations of the labelled solutions are indicated under the x-axis. '_1', '_2' and ' 3 ' are the diet replicates. $\Delta$ represent statistical differences based on one-sample t-test or binomial test $(\mathrm{p}<0.01)$. All replicates but 50/50_1 and 50/50_3 are statistically different from storing similar proportions (see above)

Fig. 5 Distribution of HUs values for all replicates. Box plots represent mean and 25 and 75 quartiles as well as minimum and maximum values with outliers represented as stars. Horizontal lines spanning across replicates (identified on the $\mathrm{x}$-axis) indicate expected HU values when solution are stored in similar proportions

Fig. 6 Example of frequency distribution for the groups fed with 50\% labelled / 50\% unlabelled solutions. 


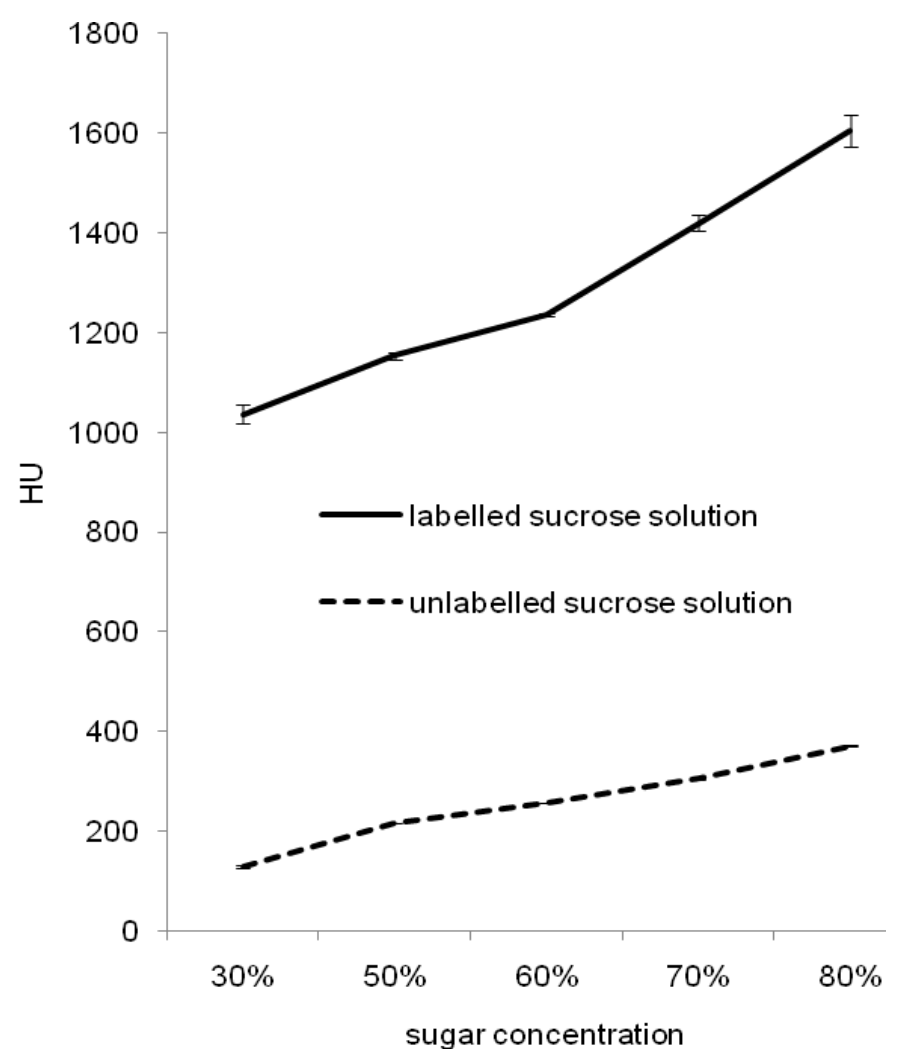

Fig. 1 


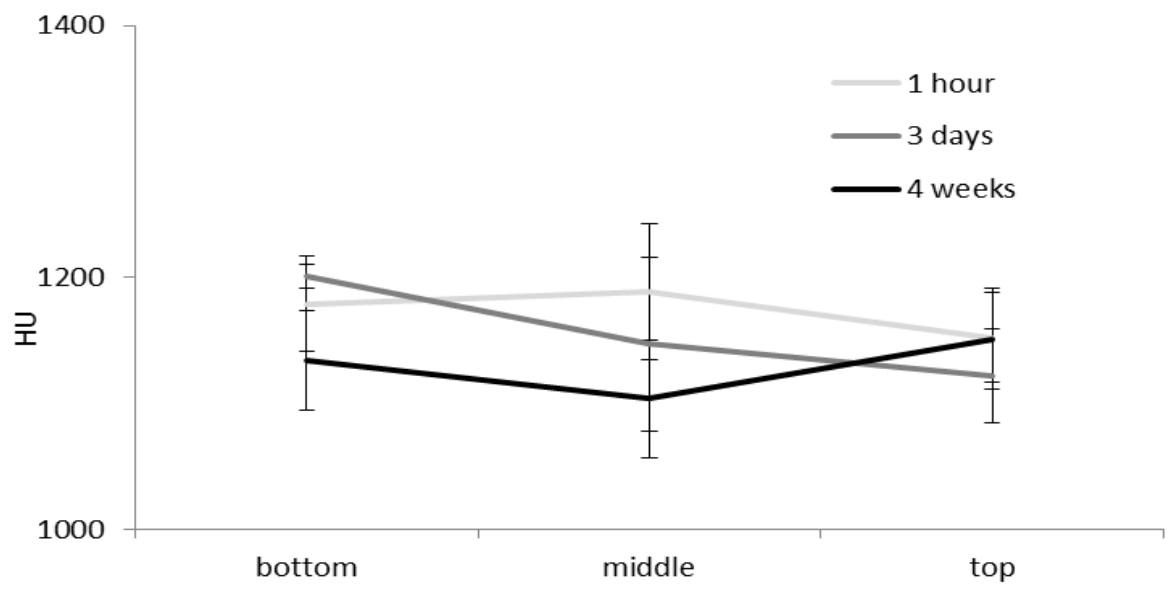

Fig. 2 


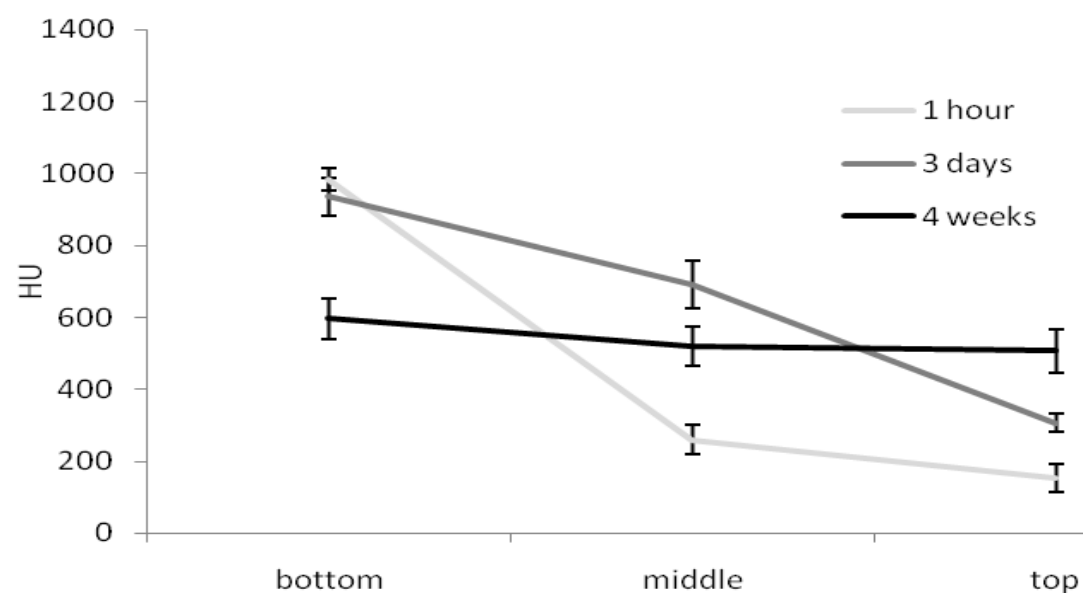

Fig. 3 


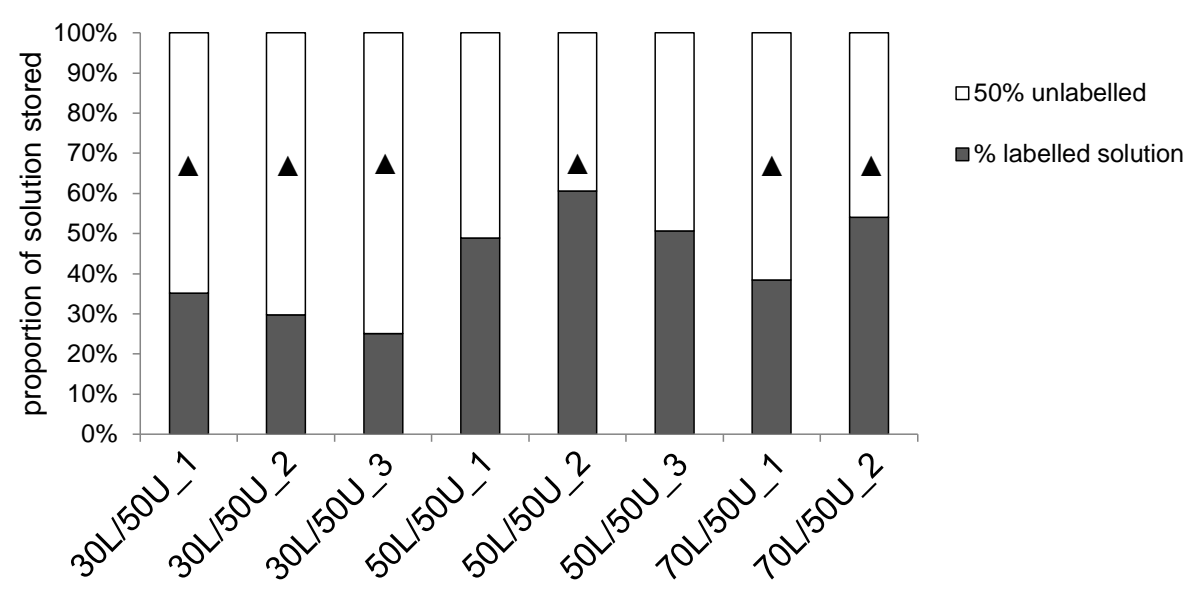

Fig. 4 


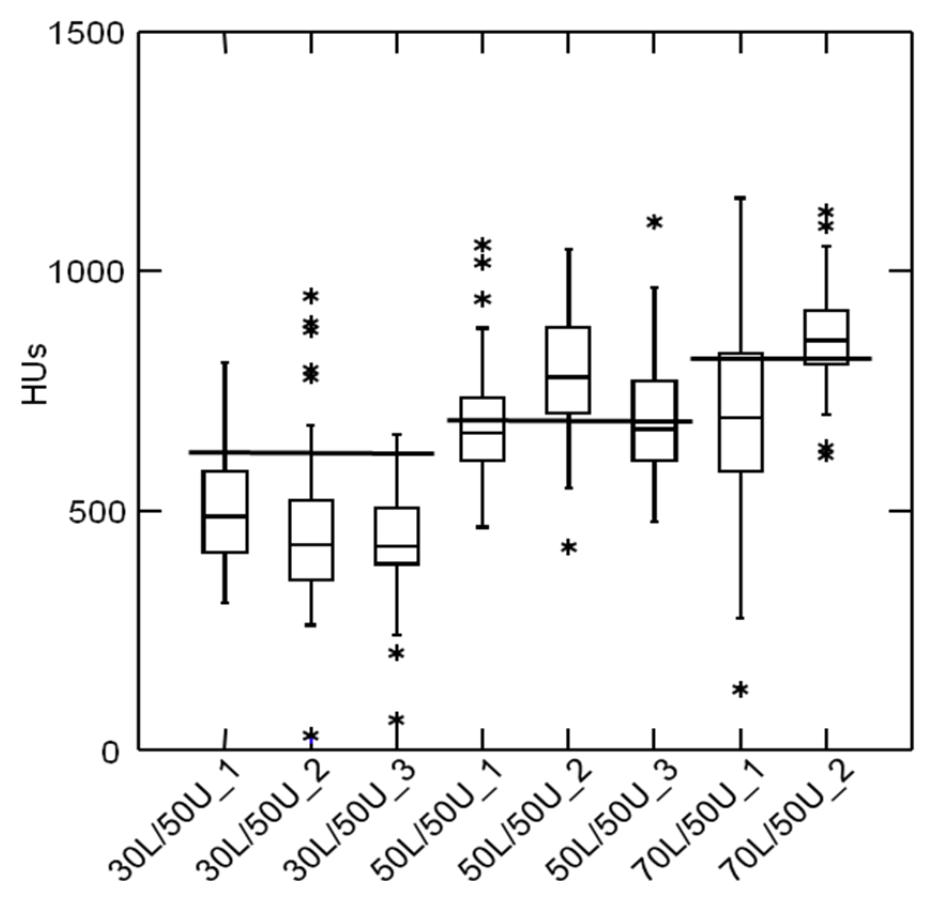

Fig. 5 


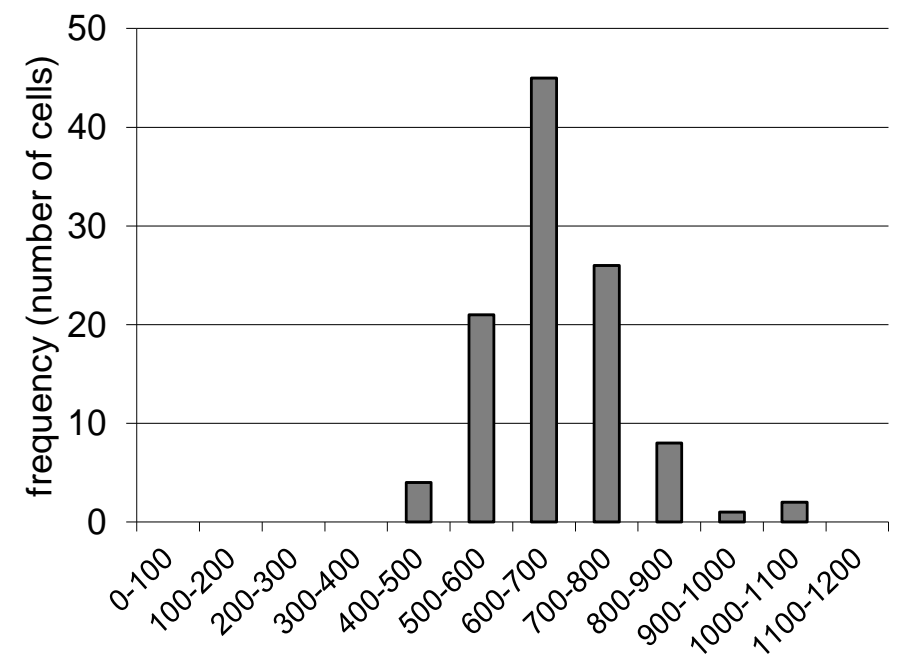

Hounsfield unit values

Fig. 6 